\title{
Lung Fibrosis in Carcinoid Syndrome
}

\author{
Gianluca Tamagno ${ }^{1,2}$, Umberto Goglia ${ }^{1}$, Giuseppe Villa ${ }^{3}$ and Giovanni Murialdo ${ }^{1}$
}

Key words: neuroendocrine tumor, respiratory failure, octreoscan, serotonin

\section{(DOI: 10.2169/internalmedicine.46.6367)}

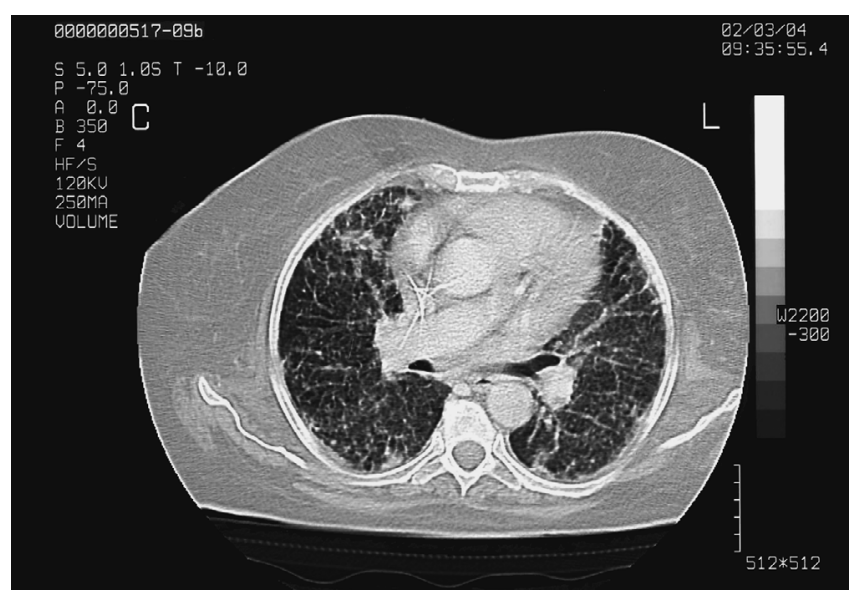

Picture 1. Diffuse interstitial fibrosis of the lungs and multiple pulmonary nodules compatible with metastasis were demonstrated by computed tomography scan.

A 59-year-old woman presented with progressive severe bronchial constriction, cyanosis, telangiectasias, erythematous to purplish flushing, abdominal cramping, watery diarrhea, and metabolic acidosis. The patient had never complained of respiratory symptoms prior to that time. She was affected by a multi-metastatic mid-gut carcinoid tumor, histologically proven by percutaneous biopsy of the liver lesion. Serotonin plasma concentration and 24-hour urinary excretion were $76 \mathrm{ng} / \mathrm{ml}$ (normal values: 5-12) and 4,390 mg (normal values: $30-180$ ), respectively. In addition to the primary neoplasia and metastatic lesions at the liver, computed tomography showed diffuse interstitial fibrosis of the lungs and multiple pulmonary small nodules compatible with metastasis (Fig. 1). Octreoscan showed an intense focal uptake of the radio-labeled tracer by numerous neoplastic abdominal lesions. Diffuse octreotide uptake at lungs and scant signs of focal enhancement at the right pulmonary hilum were evident as well (Fig. 2). Pulmonary fibrosis secondary to carcinoid syndrome was diagnosed. Other possible respiratory diseases were clinically excluded. Despite inten-

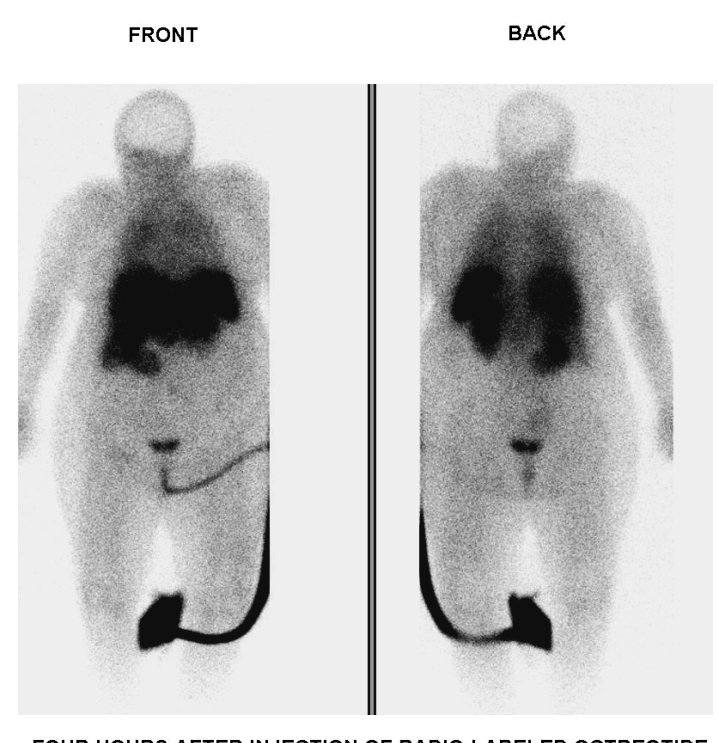

Picture 2. Octreoscan findings showed an intense focal uptake of radio-labeled octreotide by liver lesions and a nodular medial area in the abdomen. A diffuse pulmonary uptake of the tracer with scant signs of focal enhancement at the right hilum was also evident.

sive treatment with octreotide, interferon- $\alpha$, corticosteroids, ondansetron, and cyproheptadine (1), bronchostenosis and severe impairment of gas exchange with respiratory acidosis ( $\mathrm{pH} 7.238, \mathrm{pCO}_{2} 102 \mathrm{mmHg}, \mathrm{pO}_{2} 55 \mathrm{mmHg}$ ) persisted. Respiratory failure progressively worsened and the patient died. Serotonin as well as other factors secreted by carcinoid tumors, like tachykinins and TGF- $\beta$ family peptides, are able to enhance fibroblast activation and fibrosis process of the heart and, more rarely, the lung $(2,3)$, potentially leading to pulmonary hypertension and respiratory failure. In this carcinoid syndrome case, lung fibrosis was particularly relevant. Octreoscan highlighted the abdominal sites of the neuroendocrine tumor and suggested the presence, at the level of the

\footnotetext{
${ }^{1}$ Department of Endocrine and Metabolic Sciences, University of Genoa, Italy, ${ }^{2}$ Department of Endocrinology, CHU Liege-Sart Tilman, University of Liege, Belgium and ${ }^{3}$ Department of Internal Medicine, Nuclear Medicine Unit, University of Genoa, Italy

Received for publication November 10, 2006; Accepted for publication November 29, 2006

Correspondence to Dr. Gianluca Tamagno, gianlucatamagno@tiscali.it
} 
lungs, of activated fibroblasts and infiltrated lymphocytes, the cell surface and are involved in the process of interstitial which express somatostatin receptors (sst2 and/or sst5) at fibrosis (4).

\section{References}

1. Kaltsas GA, Besser GM, Grossman AB. The diagnosis and medical management of advanced neuroendocrine tumors. Endocr Rev 25: 458-511, 2004.

2. Modlin IM, Shapiro MD, Kidd M. Carcinoid tumors and fibrosis: an association with no explanation. Am J Gastroenterol 99: 2466$2478,2004$.
3. Moss SF, Lehner PJ, Gilbey SG, et al. Pleural involvement in the carcinoid syndrome. Q J Med 86: 49-53, 1993.

4. Reubi JC. Peptide receptors as molecular targets for cancer diagnosis and therapy. Endocr Rev 24: 389-427, 2003.

(C) 2007 The Japanese Society of Internal Medicine http://www.naika.or.jp/imindex.html 